\title{
Analysis of agricultural information service needs in the suburbs of Beijing
}

\author{
Yaming Zheng ${ }^{1,2}$, Changshou Luo ${ }^{1,2, a}$, Chengzhong $\mathrm{Cao}^{1,2}$, Qingfeng Wei ${ }^{1,2}$ and $\mathrm{Jun}_{\mathrm{Yu}^{1,2}}$ \\ ${ }^{1}$ Institute of Agricultural Information and Economics. Beijing Academy of Agriculture and Forestry Sciences, Beijing, China \\ ${ }^{2}$ Beijing Research Center of Engineering Technology on Rural Distance Information Service, Beijing, China
}

\begin{abstract}
A questionnaire survey was carried out on the theme of the demand for agricultural information service in the suburbs of Beijing. On the basis of the investigation, the demand of agricultural information service in the suburb of Beijing was analyzed, and the suggestions on the agricultural information service were put forward in combination with the actual situation.
\end{abstract}

\section{Introduction}

Country is the biggest demand market for agricultural information service, and farmers are the largest demand group for agricultural information service [1]. Analysis of the supply and demand, also the relevant affecting factors of agricultural information service correctly, is a new way and mechanism to improve the performance and promote the high-level and balanced development of agricultural information service, has a very practical significance for solving the contradiction between the supply and demand of agricultural information service and promoting rural economy developing rapidly [2-3].

\section{Investigation methods}

In order to reveal the characteristics of the demand for agricultural information service, this paper made a questionnaire survey on the students participating in the "new professional farmer technology promotion class of water-saving". The typical interviews, such as farmers with large scale planting or breeding, agricultural technicians, low income farmers, high income farmers, etc. were selected. The questionnaire was designed focusing on the information needs, sources, ways and obstacles of the respondents, so as to get a deeper understanding of the reality of farmers' information needs.

The participants came from the suburbs of Beijing, with a wide coverage and representativeness, are an important component for receiving and disseminating agricultural information. After collation and analysis the questionnaires, 71 valid questionnaires were obtained. Viewed by gender, male accounted for $49.3 \%$ and female accounted for $50.7 \%$. From the point of age distribution, farmers under the age of 30 took $8.45 \%, 30$ to 40 years old $33.80 \%$, 40 to 50 years old $28.17 \%$, and more than 50 years of age $29.58 \%$. The youngest was only 24 years old From the educational qualifications, People accounted for $39.5 \%$, ever joined senior school or technical secondary school. People accounted for $57.70 \%$, had got college degree or higher. The lowest degree of the respondents was junior school, which accounted for $2.80 \%$. From the situation of family income, the monthly income was main between 2000 and 4000 yuan, accounting for $43.66 \%$. The main source of income was planting and working wages, accounting for $90.14 \%$ (Table 1).

Table 1. The basic information of the study samples

\begin{tabular}{|c|c|c|}
\hline Item & Variable name & Proportion \\
\hline \multirow{2}{*}{ Gender } & Male & $49.30 \%$ \\
\hline & Female & $50.70 \%$ \\
\hline \multirow{4}{*}{ Age } & $20-30$ & $8.45 \%$ \\
\hline & $30-40$ & $33.80 \%$ \\
\hline & $40-50$ & $28.17 \%$ \\
\hline & $>50$ & $29.58 \%$ \\
\hline \multirow{3}{*}{$\begin{array}{l}\text { Educational } \\
\text { qualifications }\end{array}$} & Junior school & $2.80 \%$ \\
\hline & $\begin{array}{l}\text { Senior school or } \\
\text { technical secondary } \\
\text { school }\end{array}$ & $39.50 \%$ \\
\hline & $\begin{array}{l}\text { College degree or } \\
\text { higher }\end{array}$ & $57.70 \%$ \\
\hline \multirow{6}{*}{ Income } & $<2000$ yuan & $4.23 \%$ \\
\hline & 2001-4000 yuan & $43.66 \%$ \\
\hline & $4001-6000$ yuan & $18.31 \%$ \\
\hline & $6001-8000$ yuan & $12.68 \%$ \\
\hline & $8001-10000$ yuan & $4.23 \%$ \\
\hline & $>10000$ yuan & $16.90 \%$ \\
\hline \multirow{5}{*}{ Source of income } & Planting & $33.80 \%$ \\
\hline & Forstry & $8.45 \%$ \\
\hline & Breeding & $4.23 \%$ \\
\hline & Working wages & $56.34 \%$ \\
\hline & Others & $4.23 \%$ \\
\hline
\end{tabular}




\section{Results and analysis}

\subsection{The type of information that farmers need in agricultural production}

According to the survey, four types information were the farmers' most concerned and needed, which were agricultural science and technology information, training information on agricultural technology, agricultural policy and information of product supply and demand. The proportions were $77.46 \%, 74.65 \%, 76.06 \%$ and 74.65 respectively. Secondly, information on pest control and agricultural supply accounted for $52.11 \%$ and $47.89 \%$ respectively. Information on prevention and control of meteorological and disaster forecast was $32.39 \%$, The proportion of processing information of agricultural products was $30.99 \%$. Information on migrant workers accounted for $12.68 \%$ (Figure 1). The results showed that farmers had realized the importance of modern science and technology in improving agricultural production efficiency. The information demands of farmers were not only a single item, but for many aspects such as technology, policy, market and so on, which presented the characteristics of multi-level and multiplicity. Information related to the decision-making of agricultural production and operation, among all kinds of agricultural information, was the dominant one in the information demands of farmers.

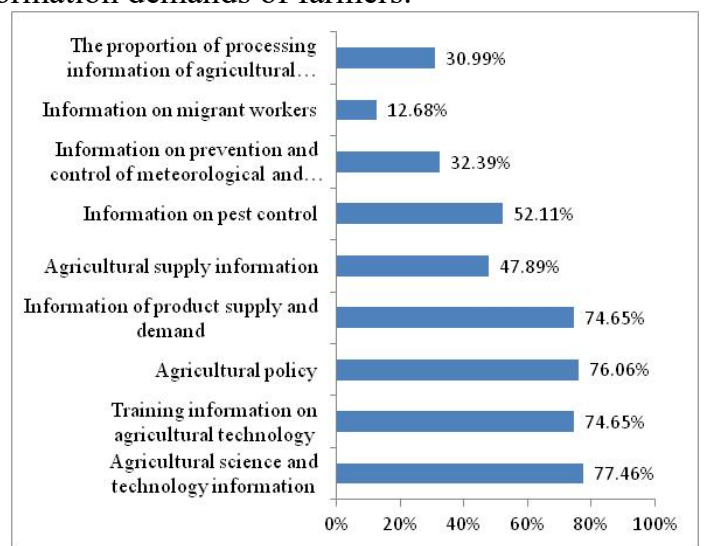

Figure 1. The type of information that farmers need in agricultural production

\subsection{The sources of information that farmers gained}

According to the survey, the main sources of information for farmers were agro-technical promotion departments, agricultural research institutes and information service institutions, accounted for $84.51 \%, 74.65 \%$ and $61.97 \%$ respectively. The information obtained through these channels was also the most trusted by farmers. The information released by researchers that summarized rich practical experience, makes it easy for farmers to accept and understand. It shows that agricultural technology promotion departments, agricultural research institutes and agricultural information service agencies play an important role in information dissemination and information services. Agricultural technicians were also playing an important role, accounting for $47.89 \%$ of the farmers who obtain agricultural information from them. The farmers who chose to obtain information from agricultural professional cooperatives and parks and agricultural leading enterprises accounted for $32.39 \%$ and $26.76 \%$ respectively. $21.13 \%$ of the farmers chose information from agricultural materials market. Although farmers contacted with the agricultural market frequently, it did not become the major source of information for farmers (Figure 2).

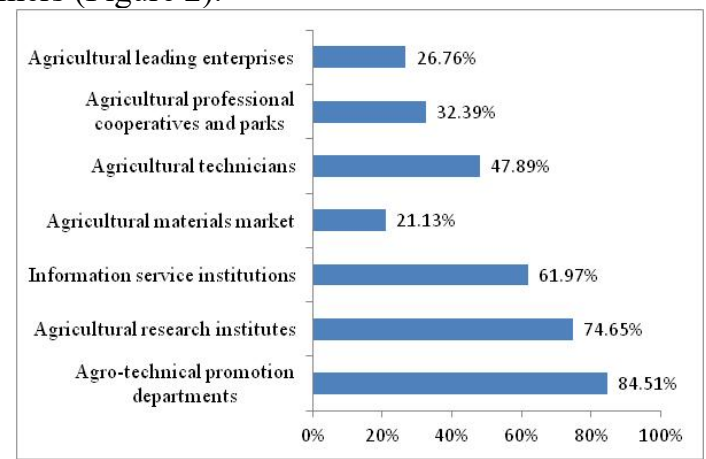

Figure 2. The sources of information that farmers gained

\subsection{The ways farmers got information}

The survey data showed that the major channel of agricultural information for farmers were the Internet (web browsing, E-mail, etc.), lectures and training, we-chat, QQ, and field observation, which accounted for $80.28 \%, 78.87 \%, 70.42 \%$ and $67.61 \%$ respectively. $50.70 \%$ of farmers obtain agricultural information through television. Mobile phones, phone were important means for personal information communication, which were directly and timely. $29.58 \%$ of the farmer obtained information by mobile phone messages, $21.13 \%$ of the farmer used telephone to obtain information. Newspapers, periodicals and video discs still played a certain role, accounted for $19.72 \%$ and $8.45 \%$ respectively. Only $5.63 \%$ of them got information through neighbors, relatives and friends (Figure 3).

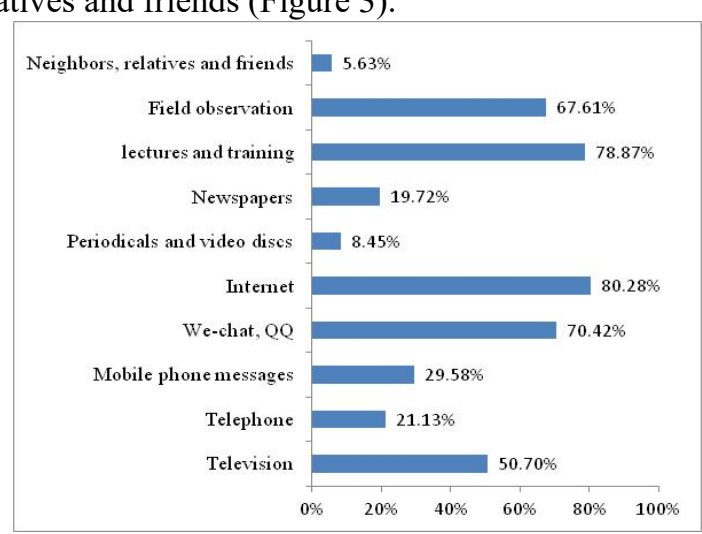

Figure 3. The ways farmers got information

\subsection{Obstacles of receiving information}

$38.03 \%$ of the farmers believe that there were obstacles and $61.97 \%$ did not have any obstacles, when receiving information normally. The main performance in the 
information transmission was not timely, the proportion was $48.15 \%$. The next was that the receiving information was not professional, no computer and did not understand the receiving information, accounted for $25.93 \%, 25.93 \%$ and $22.22 \%$ respectively (Figure 4 ).

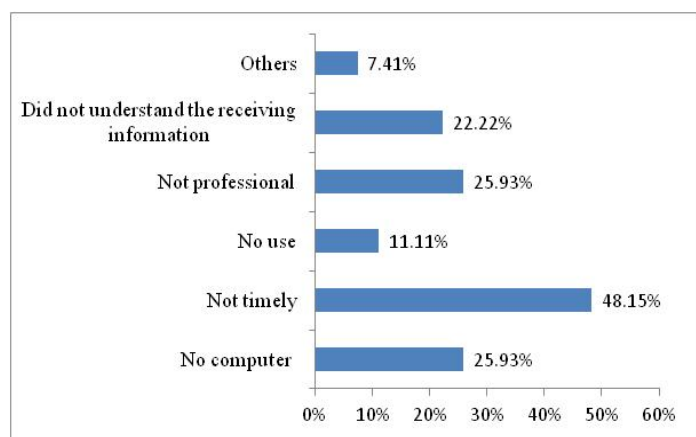

Figure 4. Obstacles of receiving information

\section{Conclusion}

Based on the above analysis and combined with the actual investigation, the following conclusions could be drawn:

The information required by farmers was mainly agricultural science and technology information, followed by agricultural policy, market supply and demand. In various agricultural information, these related to agricultural production and management decisions played a dominant role in the information needs of farmers. The main sources of information for farmers were agricultural technology promotion departments, agricultural research institutes, and agricultural information service agencies. The major channels for farmers to obtain information were internet (internet browsing, e-mail, etc.), lecture training, We-chat, QQ, etc., and on-site observations, which showed that farmers had realized that they obtain information through multiple channels of information technology. The main obstacles for farmers to obtain information were that the information transmission was not timely and not professional. The non-standard information dissemination and farmers' own economic and cultural level had become obstacles.

\section{Countermeasures and suggestions}

The service of agricultural information is a higher requirement for the agricultural information system under the rapid development of agricultural information. How to choose the best way of service according to the demand of market, to make the useful information quickly spread to the user and maximize the role of information, is the first thing to be clear for agricultural information demand, in order to make the agricultural information service better and efficiently meeting the needs of farmers [4-5].

\subsection{Information services according to the demand}

The agricultural information service should set out from the actual needs of farmers and the actual conditions of agricultural production in different regions, which could provide pertinent and practical information to farmers. Some information channels suitable for farmers and high efficiency of information dissemination are needed to be developed. The construction of agricultural information resources and market supervision should be strengthened. More new agricultural technologies, agricultural information about product supplyment and demand, agricultural policy are needed to be delivered to farmers timely, which could provide reliable information for farmers' production and rural construction.

\subsection{Integration of agricultural information resources}

To provide integrated information services for agricultural production, incomes and rural development, integrate agricultural information resources, opening access and resource sharing of agricultural information systems with various departments should be established. We also need to improve regional resources contribution, avoiding redundant construction, which could save manpower and material resources.

\subsection{Perfecting the supervision and management of the legal system}

To improve the mechanism of agricultural information risk protection, and to enhance the capacity of farmers to bear agricultural information risk, the agricultural information supervision institutions and information legal system and regulations should be established and improved to ensure the authenticity and effectiveness of information.

\subsection{Hierarchical training}

Agricultural information education and training should be carried out at different levels, for different cultural levels and information needs, such as, the use of smart phones, APP applications, information browsing and publishing of agricultural information websites et al. So that farmers could learn to apply modern information technology and find information they need in massive information quickly.

\section{Acknowledgement}

The research work was supported by the young scientist fund of BAAFS: Analysis of omnipotent agricultural technicians' training effect and relevant affecting factors in Beijing (NO.QNJJ201803), the Beijing excellent talent project: Research on key technology of man-machine conversation in agricultural science and technology consultation and application of Beijing, Tianjin and Hebei, the international cooperation fund of BAAFS: A 
comparative study on the agricultural science and technology information service system in China.

\section{References}

1. Y. Ren, F. F. Guo, J. Shanxi agricultural science, 1018-1020, 43, (2015)

2. F. C. Zhu, China agricultural information, 20-24, 3, (2017)

3. S. W. Fu, S. Zhao, L. L. Shi, X. Z. Liu, J. S. Wu, G. F. Chen, L. Y. Cao, Agriculture network information, 81-84, Informatization service, (2018)

4. L. Q. Bai, Library and information work, 63-66, 61, (2017)

5. Y. P. Ma, Agricultural library and information science, 121-128, 11, (2017) 